\title{
Is It Possible to Improve Efficiency of BiH Decentralisation Model: Comparative Analysis of Decentralisation Solutions and Relevance for BiH Context
}

\author{
Aida Soko \\ School of Economics and Business, University of Sarajevo, Bosnia and Herzegovina
}

Copyright $\odot 2018$ by authors, all rights reserved. Authors agree that this article remains permanently open access under the terms of the Creative Commons Attribution License 4.0 International License

\begin{abstract}
Dayton Peace Agreement (DPA) has resulted in asymmetric decentralization in Bosnia and Herzegovina $(\mathrm{BiH})$ in all aspects: political, administrative and fiscal. Decentralization driven by non-economic reasons is rather usual concept, and often the main reasons are political, ethnical or overall country stability. Decentralization model implemented in $\mathrm{BiH}$ became huge obstacle not only in reaching efficiency in provision of public services, but also to further economic development. While the purpose of DPA was to stop armed conflict, and while valuable back in time, there is no excuse to keep these solutions for more than 20 years. This paper aims to provide deep insight into experience of selected comparative countries where non-economic reasons initiated decentralization. In addition, it aims to identify patterns and features of administrative, fiscal and political arrangements that perform better in the environment similar to $\mathrm{BiH}$. Analysis of the experience in developed countries identified different models in organizing ethnically divided societies and establishing different forms of cooperation between sub-national government units to increase efficiency. Transitional countries experience shows mixed results in terms of positive effects of decentralization on overall efficiency and citizens' well-being, but there is valuable experience and number of features, which may improve municipal efficiency in $\mathrm{BiH}$ as well. Having in mind very limited literature focused on specific $\mathrm{BiH}$ context as well as the need to improve efficiency at local community level, this paper takes an important first step in this direction by providing a systematic review of decentralization design in countries that had similar challenges as $\mathrm{BiH}$. The focus of comparative analysis is on the administrative decentralization (territorial organization and responsibility designation), political decentralization (addressing democratic principles) and fiscal independency. Paper has identified certain mechanisms that do not require any or
\end{abstract}

require minor changes in core legislation introduced by DPA. These primarily include activation of cooperation mechanisms already allowed by law as well as improving system of revenue and grant allocation. Democratization still did not reached proper level as mechanisms introduced by DPA do not address rights of minorities, and this has to be changed. Improving municipal efficiency in $\mathrm{BiH}$ by applying experience of developed and transitional countries therefore may range from better cooperation according to the existing laws, to substantive changes of legislation.

Keywords Comparative Analysis, Decentralization, Intergovernmental Relations, State and Local Government, Transitional Countries

JEL Classification: H77, H11

\section{Introduction}

In last two decades decentralization become one of the most popular trends in public sector management. Many developed and transition countries have taken this path aiming to increase efficiency in provision of public services, but also to ensure balanced citizens engagement in decision-making processes.

DPA decentralization framework became major obstacle in reaching efficiency in public services provision. DPA established complex asymmetric government structure with two entities: Federation $\mathrm{BiH}(\mathrm{FBiH})$ and Republic of Srpska (RS) and one district (Brčko), rotating three-member presidency and bicameral parliament (s). In FBiH subnational government has three tiers: entity, 10 cantons and 79 municipalities, each having its own 
parliament/assembly, while RS has two tiers of subnational government: entity and 62 municipalities. Two major mechanisms are in place to guarantee ethnic representation: quotas at government and civil service, and veto rules at the parliament level.

There is no doubt that stability of post-conflict divided society in $\mathrm{BiH}$ was important part of constitutional design and efficiency framework. In general, government units have high level of autonomy, and vertical and horizontal cooperation between different levels of government is quite poor. In general, $\mathrm{BiH}$ legislation is compliant with European Charter on local self- government, but there are also a number of deficiencies observed. These deficiencies mainly refer to the constitutional guarantees governing the relations between the various levels of local self-government, overlapping and/or lack of clarity of powers between different government levels, fragmentation of the territory and very limited inter-municipal cooperation.

$\mathrm{BiH}$ has a long history of strongly centralized system. However, centralization and decentralization are not concepts that exclude each other. In practice, it is hard to find examples of completely centralized or fully decentralized state. The efficiency and functionality of government is result of proper balance between these two concepts. While in theory, the classical views respect the theory of symmetry, specifics of different countries call for more flexibility in designing functional system of decentralization and applying asymmetry in organization of government units. Asymmetry may be legal or factual (de jure or de facto) and implemented in the whole territory or just in one part, as it is case of Spain and Canada, for example. The criticism of asymmetric decentralization considers this model as inefficient way of reaching allocative role of the government, with no advantages over centralism. So called "Federalism a la carte"[1] preserve asymmetric level of development[2] and led to even deepening the gap between developed and underdeveloped local communities[3]. In making decision about decentralization, it is important to understand that there is one optimal solution, but each country has to find its own optimal solution. Although decentralization become worldwide accepted as a trend, the results in terms of efficiency and quality of public service, so far show mixed results due to the different institutional capacities of countries undertaking such reforms. Hence, this paper explores functional mechanisms and options that may improve efficiency in provision of public services in $\mathrm{BiH}$.

\section{Decentralization History in Bosnia and Herzegovina}

The history of $\mathrm{BiH}$ was quite turbulent with many changes of jurisdictions in relatively short period. Until 1992 independence, $\mathrm{BiH}$ public sector was strongly centralized system whereby local communities were rather executive part of the government. Since its independence, $\mathrm{BiH}$ has passed through a number of reforms, which had impact on the sub-national government structure, scope and fiscal relations. The major milestone was DPA, which has drawn some new borders and has created new territorial units. Although, division of powers and responsibilities defined by DPA are highly inefficient, there is very little chance to reach consensus on any changes, as it becomes primarily political issue.

Back in history, Austro-Hungarian monarchy (1878-1918) has overtaken administrative and territorial organization of $\mathrm{BiH}$ by Ottoman Empire, and military persons who were at the same time commanders of local troops have chaired the Government of $\mathrm{BiH}$. Decision making power was centralized in Vienna while sub-national government was executive part of the system consisted of complex system of counties (6), regional offices (59) and 22 counters (22), city municipal administrations (66) and village municipalities (2.195). Reforms after the First World War by Vidovdan Constitution have reduced sub-national government to three levels: municipality (2.228), region (51) and county (6), still keeping strong centralization in terms of decision making. First forms of democratically elected government appeared during the Second World War, when, so called "NOOs" have been created at village and municipal level. However, centralization remains to be main feature of public sector governance in $\mathrm{BiH}$ until declaration of independence from Yugoslavia in 1992. By different reforms, local communities started to manage certain public services and number of municipalities dropped to 109 . Declaration of independence caused four years of armed conflict, which ended by signing DPA in 1995.

DPA introduced changes of administrative and territorial organization has been by introducing entity level and creating 33 new municipalities, mainly to accommodate ethnic and political requests. As a result, $\mathrm{BiH}$ became a federal state consisted out of two entities ( $\mathrm{RS}$ and $\mathrm{FBiH}$ ) and one District. Brcko district has a special status given by Annex 2 of DPA and although the status of district was supposed to be temporary, one-year solution, it remains unchanged until today. In RS there are 62 municipalities/cities while in $\mathrm{FBiH}$ there are 10 Cantons which are further divided into 79 municipalities/cities.

According to the Law, municipality is a local unit of self-government with prescribed jurisdictions that cannot be limited or denied by upper government. Cities are established through an agreement of two or more municipalities, or be given such status by upper level of government. The legislator have to obtain the opinion of the Association of Municipalities and Towns on all issues that concern allocation of funds, as well as on all changes to laws that may affect financial obligations of local communities.

However, there is no one single Law at State level 
regulating the status of local communities, but there are two Laws at entity level. The provisions of entity laws are not harmonized which resulted in many unclear provisions and numerous overlapping and conflicting provisions. Local Communities filed many court processes at Constitutional Court due to violation of local community rights by upper government levels, namely Cantonal, Entity and State level. In principle local communities are in charge for: Planning and Budgeting, Local public infrastructure and property management, Protection of public goods and natural resources as well as environment protection policies, Preschool and primary school education, Natural disasters protection, Raising local taxes and fees and Maintaining personal status of citizens and electoral rolls. The listed activities are inherent jurisdiction of the local community, but they may also conduct delegated activities, through joint agencies, services, organizations and institutions with public authority, and through other forms of cooperation.
Local communities have a Mayor and Municipal Council, both elected directly by citizens every four years. Voters may choose among listed candidates for Mayor and candidates for Municipal Council. While voting for Municipal Council members, voters may vote only for one party i.e. if he or she decides to vote for individuals listed, all of them need to be from the same party.

To perform all assigned activities local communities secure funding sources from transfers from state level, local taxes and fees as well as donations, grants, loans and similar sources. For majority of municipalities, allocation of funds from upper levels of government is dominant source of funding. In average about $65 \%$ of funds in municipality budget, originate from these transfers. Entity Laws regulate allocation of funds to local communities by prescribing allocation criteria and formulas based on the principles of solidarity and fiscal balance.

Chart presents distribution of taxes collected at the State level towards sub-national governments:

\section{State $\mathrm{BiH}$}

(minus State budget financing)

(minus Brcko district financing)

funds to be allocated to entities based on final consumption to

\begin{tabular}{|c|}
\hline FBiH \\
\hline (minus foreign debt payment) \\
$=$ funds for distribution \\
\hline
\end{tabular}

FBiH budget $36,2 \%$

Cantonal budgets $51,5 \%$

Municipal budgets $8,4 \%$

Road directorate $3,9 \%$

\section{RS}

(minus foreign debt payment)

= funds for distribution

RS budget $70 \%$

Municipal budgets $30 \%$ 
Entity Laws on distribution of public revenues regulate percentages of distribution towards sub-national levels. In $\mathrm{FBiH}$, Cantons are in charge for health care, education, culture and social issues, as well as any other area of special interest of the Canton. Entity and municipalities share the funds allocated to RS. The allocation formula for transfers to local communities includes certain criteria such as number of inhabitants, territory size and number of pupils in primary schools. Municipal taxes are quite limited and include property tax, property transfer tax, certain types of concessions on natural resources and some fees charged at municipality level.

In general, $\mathrm{BiH}$ decentralization model is rather complex administrative set up heavily affected by ethnic aspirations, mixed interpretation of basic political decentralization rules and very limited fiscal independency. Many authors $[4,5,6]$ agree that the tremendous complexity and inefficiency of the political system in BiH have arisen out of specific consociational provisions of DPA constitution. The DPA is typical form of consociationalism whereby ethnic groups are accommodated according to ascriptive rather than self-determined criteria [7, 8, 9]. Consociational democracies [10] are characterized by: Proportionality (representation based on population in civil service and other segments of society), Segmental autonomy (allowing for different culturally-based community laws), and Grand coalition (political elites cooperate to preserve status quo), and Mutual veto (consensus among groups is required and it often results in blocking decision making process).

\section{Decentralization Experience in developed and Transition European Countries}

European Charter of Local-Self Government is a legal tool and guidance in defining and legally guaranteeing autonomy, aiming to define basic principles in local self-government in terms of transfer of competences and resources, safeguards to protect local community rights and guaranteeing the independence of elected officials. Charter is guidance, not a prescription and it is embedded in European legal systems, but using different decentralization models, best adjusted to the specifics of different countries.

Majority of countries in Europe are unitary, except five organized on federal principle: Austria, Bosnia and Herzegovina, Belgium, Germany and Switzerland. The number of government tiers varies from one to three, but majority of European countries have two tiers of sub-national government. Having in mind huge differences in population, the most relevant measure of government closeness to the people is average population of $1^{\text {st }}$ tier of government. According to EUROSTAT data for year 2014 average population at local communities, varies significantly from 1.686 in Czech Republic to 148.984 in UK. The degree of decentralization, and in particular fiscal decentralization, also varies significantly, from highly decentralized countries such as Switzerland, Sweden and Germany to very low level of decentralization such as observed in Portugal, UK and Luxembourg. The trend of increasing degree of decentralization is present in majority of European developed countries, but also some adverse processes happened, although with slight effects, in particular in Scandinavian countries [11, 12, 13].

The share of sub-national taxes in total taxes collected represents important factor in reaching efficient decentralization framework. In conducting out delegated responsibilities, sub-national governments need financial independence and therefore fiscal decentralization is one of the major preconditions to set effective and efficient framework for public services. Still, even in most decentralized countries, the share of local taxes in total taxes collection is relatively low. According to the OECD Fiscal Decentralization Database 2014, the top five developed European countries in terms of share of sub-national taxes in total taxes are Switzerland (39.8\%), Sweden (37.1\%), Spain (35.5\%), Germany (31.1\%) and Denmark (26.5\%).

There is no agreement among economists about existence of empirical evidence on decentralization effects on quality and efficiency of public service delivery, and in transition countries, it becomes even more complex to measure effects. Often, the reasons for decentralization reforms are not economic and social, but political and bounded by limited institutional capacity at both levels: national and local. There is very low level of coordination between different levels of government as well as with other stakeholders, like unions, private sector, NGOs, academia etc. In particular, in transition countries decentralization reflects political, historical, ethnic and demographic differences. For larger countries, decentralization addresses efficiency while in smaller countries it may be result of ethnical diversities, or political factors such as EU accession [14].

The transition countries mainly had strong centralized systems and changes of constitution, in particular in Balkan and Caucasus countries, posed a challenge of decentralization as a major change in making society more efficient. The types of centralization varied from closed highly centralized system like Albania, to more relaxed systems such as ex-Yugoslavia. Political instability, collapsed systems, new countries with limited experience in running a state administration were not ideal starting point to create well-functioning decentralized system. Formally, these countries have adopted principles defined by the European Charter of Local Self Government. However, the lack of previous experience with market-based decision- making has affected heavily the path of decentralization and limited efficiency of reforms. In principle, transition countries implemented 
decentralization in already existing local communities, inherited from completely different, centralized system whereby efficiency was not a major concern. It lacks of structured approach to set best decentralization framework for transition period. Centralized systems had strong and clear rules, easy to follow by local communities, which had very limited jurisdictions and very low fiscal independence. Therefore in majority of transition countries decentralization resulted in small, fragmented subnational governments with low capacity to address challenge of taking new jurisdictions and responsibilities as well as overtaking more responsibility in managing local community development. While in centralized system expertize was concentrated at state level and equally distributed to all local communities, suddenly after decentralization it become dependent on local expertize and capacity of local government. Major obstacles to successful implementation of decentralization in transition countries include inappropriate legal framework, lack of strategic approach, capacity of central government, and accountability of local government. Most quoted unwanted effects of decentralization are exhibit in small fragmented subnational governments [15], which are good ground for creation of elites, special-interest groups, corruption, clientelism and nepotism [16].

One of the major challenges is to reach economy of scale in decentralization concept, but there is lack of any pattern in terms of correlation between number of government tiers and average population per municipality. The average size of municipality in transition countries varies significantly from 2.000 inhabitants per municipality in Turkey to 65.000 as average in Georgia. Among transition countries, only Ukraine and $\mathrm{BiH}$ have three tier sub-national governments, while Montenegro, Kosovo and Georgia do have only one tier. In addition, transition countries in principle have quite high concentration of the population at the capital city about one third of total population, which create political and administrative impediments to decentralization. Within this framework, it is relatively difficult to assign proper revenues to municipalities or to create good equalization mechanisms and often it results by conflicts between capital city and other municipalities.

Hence, there is no single model as best practice, but specific experience of some countries may be very useful in terms of reshaping administrative and territorial organization in $\mathrm{BiH}$, improving efficiency of public sector, and in particular efficiency of local communities. Some interesting features of decentralization concepts applied in Sweden, Belgium, Switzerland, FYR Macedonia, Croatia and Slovakia may be useful for $\mathrm{BiH}$ context as summarized in further text.

\section{Swedish model}

The Swedish model is one of most discussed growth models, thanks to tremendous improvement of economic wealth within only one century. By international comparison, Sweden has high degree of decentralization and very light supervision system. The major characteristic of Swedish model, relevant for BiH includes:

\section{- Proper balance between public and private sector} role. Sweden has large privately owned industry, large public sector financed by taxes, strong trade union and active role of state in labor market policies and most important, and focus on even distribution of income and wealth. Sweden has supported private sector by extensive grant subsidies to affected industrial sectors, steel and shipbuilding, for example. At the other side, heavy tax burden followed expansion of public sector. Unlike to Sweden, BiH has low tax rates, underdeveloped private sector and weak unions, hence Swedish model may be good pattern in reform design. Instead of focusing on reducing public sector, which requires constitutional reform, the focus on targeted support to private sector development and increase of tax revenue may be equally efficient.

- Improved efficiency of the public sector through introduction of horizontal cooperation models. Municipalities or county councils may enter into local federations for cooperation on variety of local authority matters, or into so-called common committee. Local federation is a legal entity and governance bodies elected by assemblies of the federation members manage transferred competences. Unlike to local federation, common committee is not a legal entity, but is part of the organization of one of the municipalities engaged in the cooperation [17]. There are about 95 local federation and 70 common committees, mainly organized for rescue services, education and environment. Possibility of cooperation exists in BiH legislation, but is not usual practice. The forms of local federations and common committees could be very effective tool in BiH to improve quality in providing certain public services due to high discrepancies in terms of cantonal institutional and financial capacities.

- The responsibilities assigned to counties are asymmetric. Usually, there are two main institutions at county level: County Council and County administrative board headed by central government appointee. County Councils are responsible for Health care and Children and Youth dental care, both being mandatory tasks accounting for over $95 \%$ of total expenses, while voluntary tasks include culture, education and tourism. Introduction of this principle in $\mathrm{FBiH}$ would result in asymmetric solutions towards Cantons by taking into consideration their capacity to serve citizens in certain areas, as the size and economic wealth of the Cantons in FBiH varies significantly. 
Cooperation mechanisms embedded in such asymmetric solutions may significantly improve quality of services in health care and education, which are in jurisdiction of Cantons.

Cultural and Ethnic Pluralism in Belgium

The cultural pluralism is important feature of Belgium state addressing the challenges in terms of differences in language, culture and preferences. Therefore, reforms in Belgium mainly aimed at addressing non-economic issues and resulted in low level of fiscal decentralization. Several features of decentralization in Belgium may be of useful input in redesigning $\mathrm{BiH}$ national and sub-national government system:

- Setting up cultural communities. Belgium has three cultural communities as specific form of administrative organization financed by lump sum grants. Two accords, Lambermont Accord and the Lombard Accord provide legal framework, and grant responsibilities over education, elderly, child and health care through devolution of powers and specific distribution of seats between the linguistic groups within communities. The current system in BiH is trying to accommodate cultural and ethnical requirements by administrative and territorial solutions, which is creating very complex system. Instead of addressing only ethnic, cultural and language issues, BiH has ethnical controlling mechanisms over all legislative and regulatory matters. Introduction of Communities would address specific issues of ethnic groups and would enable other administrative units to focus on economy and efficiency, which are equal for all ethnic groups.

- Equal power of government units and clear division of responsibilities. The Federal State, the Communities and the Regions are equal from the legal viewpoint, but have jurisdiction over different areas. One of these three units supervises Provinces and Municipalities depending on particular area of jurisdiction, but in general, they mostly financed and supervised by the Regions[18]. Federal state is in charge of judicial system, army, police and foreign affairs, Communities have responsibility over culture and education, while Regions, Provinces and Municipalities share all other areas. The principle of equality is crucial for BiH to reduce the fear of losing control over the areas important to certain ethnic groups. Introduction of Communities with jurisdiction over culture and education would address this issue. Also, clear division of responsibilities is very important for BiH as current system has many overlapping between different government levels.

Switzerland Federal Constitution
The three main principles dominate Switzerland constitutional regime: autonomy, subsidiarity and consensus. Before establishing federal constitution in 1848, Switzerland was loose confederation of states and since than number of reforms took the place [19] granting more power of cantons to influence federal level activities. Although the concept of strengthening Cantonal power may raise some political concerns in $\mathrm{BiH}$, some of the solutions of Swiss system may be very useful in $\mathrm{BiH}$ context:

- Horizontal cooperation treaties. In Switzerland, Cantons may enter into concordats - horizontal cooperation treaties to increase efficiency in services where provision is beyond their capacities. Inter-cantonal concordats are of technical nature and focus on pragmatic cooperation on the issues such as health care, road infrastructure, education, science and culture. The effects of such treaties in BiH context may significantly increase quality of services, in particular for health care and education. BiH is small country by population and land size and therefore in many cases there are "fake" migrations of population towards financially wealthier cantons ${ }^{l}$. Horizontal cooperation would allow for better use of resources and reaching economy to scale rather than duplicating services ${ }^{2}$. As BiH relatively small country by size, it would not affect principle of "closeness to the people", but rather significantly increase efficiency and quality of public services.

- Systematic controlling mechanisms. There is no government body as the state level in Switzerland to monitor distribution of powers, it is rather a system incorporated in all levels of government. $\mathrm{BiH}$ has inherited the institutional control approach from Yugoslavia. Nevertheless, ethnical quotas and latent ethnical conflict prevent these institutions to be effective. Instead of empowering individuals and institutions to perform controls and inspections, BiH shall embed controlling mechanisms into monitoring systems.

- Consensus. Cantons may change any of federal powers by reaching consensus, while even citizens may initiate changes of legislation by collecting 100,000 signatures. While there is many individual attempts by municipalities and cantons in BiH to decrease federal powers, there is no systematic

\footnotetext{
${ }^{1}$ For example, each canton provides full scale of health care services, but the quality significantly differs. Therefore, citizens decide to live in one, but register its residence in neighbouring canton, if there is better health care service.

${ }^{2}$ The distance between some cantonal hospitals providing secondary and tertiary treatment is only 30 kilometers. Concordats may allow specialization of cantonal hospitals i.e. if one canton provides specialist care for cardiology, there is no need to have the same service only $30 \mathrm{~km}$ away.
} 
mechanism of making consensus i.e. having joint interest of sub-national governments.

\section{Asymmetric Decentralization in FYR Macedonia}

FYR Macedonia has similar history as $\mathrm{BiH}$ and ethnic conflicts were part of gaining independency and developing the governance system. Independence declared 1991 resulted in ethnical conflicts and political instability for more than decade i.e. until signing Ohrid Framework Agreement (OFA). The OFA goals were twofold [20]: to address the grievances of the Albanian community [21] and concerns of Macedonian majority to preserve unitary state [22]. Both, OFA and DPA aim to address ethnic issues through specific design of decentralization framework.

- Granting special rights to local communities. The OFA grants some special rights to local communities, such as second language, equitable representation in public sector institutions, double majority-voting, arbitration mechanisms in form of parliamentary and municipal Committees for Inter-Community relations. Instead of uniformed decentralization system, BiH may consider asymmetric solutions adjusted to the specifics of certain local communities. DPA solutions are based on 1991 census, while the latest, 2013 census showed that ethnical map was significantly changed and ethical groups get more concentrated in certain areas. Therefore, the ethical rules prescribed by DPA have no sense as reality get significantly changed and these rule do not contribute to democracy, but just become burden to municipal efficiency.

- Gradual transfer of responsibilities. In first phase of decentralization, municipalities got very limited powers and responsibilities. Government established the Commission for the Monitoring and Assessment of the Municipalities with main task to assess the extent to which municipalities meet conditions to enter a Second Phase of Decentralization [23]. In second phase of decentralization, upon fulfilling prescribed criteria, municipalities get additional responsibilities. Political and administrative aspect of decentralization is more-less finalized and there are very low chances to reach consensus on any structural changes. However, BiH has relatively low level of fiscal decentralization, and criteria for on transferring more fiscal powers could be strong incentive to municipalities to improve efficiency.

Democratization and Decentralization in Croatia

Croatia and $\mathrm{BiH}$ are of the similar size, similar set up of sub-national government, and unfortunately share similar history of ethnical conflicts. Declaration of independence 1991 has caused an armed conflict that shaped the attitude of public sector towards (de)centralization [24]. The major characteristics of first government structure in Croatia were highly centralized financial flows and authoritarian decision-making ${ }^{3}$. EU accession aspirations pushed democratization of Croatian society [25] and public sector reforms undertaken to meet EU requirements. Croatia joined EU 2013, while BiH got a candidate status in 2016. Having in mind $\mathrm{BiH}$ commitment to join EU, Croatian experience may be very valuable input for public sector reforms:

- High degree of autonomy on county level. Counties in Croatia have relatively high degree of autonomy and both sub-national layers of government exercise its right based on subsidiarity principle. There is a legal framework for power distribution between different levels of government, which clearly defines roles, and responsibilities for each of subnational government units. By embedding subsidiarity principle at county level, Croatia established balance between efficiency and quality of public services. Having in mind the similar size of population and land area, applying subsidiarity principle at Cantonal/Regional level in $\mathrm{BiH}$, seems to much more efficient. Applying this approach in BiH, would increase quality of many public services due to economy to scale.

- Capacity building of local communities. Another important outcome of Croatian EU accession efforts event was intensive capacity building of local government units to manage the funds that will be available within the Community Cohesion Policy. This important issue is neglected in $\mathrm{BiH}$ and sub-national governments (Entities, Cantons and Municipalities) are expected to improve institutional capacities using own resources, without planned and structured approach. Due to weak institutional capacity, BiH has low level of usage of Pre-Accession Funds and accelerated capacity building is a key to access funding.

Resolving political obstacles - case of Slovakia

Unlike to $\mathrm{BiH}$, Slovakia is a unitary state with de-concentrated state administration and independent regional and local government. However, Slovakian case is interesting for $\mathrm{BiH}$ context due to the path of public sector reforms and the pitfalls in the process caused by strong political opposition to decentralization process. Slovakia had no ethnical issues, neither violent process of getting independence, but still had trouble in implementing reforms due to the lack of political consensus. As one of the two successor states of former Czechoslovakia, Slovakia gained independence back in 1993. The major issue in public sector reform was actual politicization of civil service

\footnotetext{
${ }^{3}$ For example, President had a veto on appointing democraticaly elected officials.
} 
lasted until 2013 and so-called ESO reform. While today's administrative set up fragmentation and implementation of subsidiarity principle reflects high level of local democracy, Slovakia is far of reaching effectiveness and efficacy [26].

- De-concentration. Slovakian decentralization framework is a dual system composed of deconcentrated State administration and autonomous regional and local self-government. State administration has two streams: general and specialized whereby general deals with "usual"4 state level administration and specialized provides public services through its regional and local offices i.e. through de-concentration of service provision. De-concentration may be useful tool in $\mathrm{BiH}$ to address huge gap in quality of public services between local communities. The gap is result of differences in fiscal and institutional capacity of rather small local communities that cannot reach economy to scale. Centralized planning and de-concentrated provision of uniformed public services would address disparities and would provide same quality of public services to all citizens' regardless economic power of sub-national government units.

- Introducing legal framework for fiscal discipline. Lack of funding at sub-national level and poor fiscal discipline were reasons to introduce audit of effectiveness and efficiency of sub-national governments. The laws in Slovakia prescribe strict rules for local communities to enter into debt arrangements and even prescribe fines in case of breaching these rules. Having in mind similar mentality of transition countries, fiscal discipline is not something to be expected. BiH is not an exception and many municipalities are rather ready to enter into a debt than to improve efficiency and manage costs. Therefore, strict rules may be very useful tool in mentality change.

\section{Conclusions}

The need for constitutional reform primarily arises from efficiency concerns and the ability of $\mathrm{BiH}$ to assume obligations on the way towards EU membership. The process of European integration, have been proven as a successful mechanism for resolving inter-state conflicts in Europe after the Second World War and therefore is crucial to $\mathrm{BiH}$ efforts as well. Finding a proper balance between efficiency and preserving democracy is very sensitive and complex process in $\mathrm{BiH}$. $\mathrm{BiH}$ society is divided at many levels, economical, administrative, territorial, ethnic, political, all having different interests and aspirations. Although it looks like mission impossible in given context,

\footnotetext{
${ }^{4}$ Security, foreign policy, monetary policy, state budgets and legislation.
}

there is a number of success stories at local government level which confirm that is possible to reach efficiency even in current circumstances.

Two major issues needs balance: building up efficient administrative capacity and preserve democratic representation. The importance of politics in fiscal decentralization shall not be undermined; it is always about vertical power and allocation of resources. The limited success of decentralization reforms and slow pace in implementing decentralization measures is signal that something went wrong in the whole concept.

Asymmetric decentralization in BiH defined by DPA is unsurmountable obstacle in reaching municipal efficiency. There is no doubt that major success of the DPA was to stop the armed conflict, but design of the constitution assumed an "ancient hatreds" conflict and "mosaic multiculturalism". Ancient hatreds means that BiH ethnic groups are recognized as fixed, naturalized and inherently conflictual and "mosaic multiculturalism" is form of coexisting, while maintaining firm boundaries [27].

However, ethnic roots are not only source of $\mathrm{BiH}$ state structure inefficiency. The number of government layers, unclear division of responsibilities and jurisdictions, lack of coordination mechanisms, and number of legislatures, governments and ministries are real obstacles to efficiency. As a country of 3.8 million people, $\mathrm{BiH}$ has 14 legislatures, 14 governments, 13 Prime ministers, and about 140 ministers. Majority of budgets are in function of financing public servants, rather than increasing quality of public services or expenditure on capital investments.

The inefficiency of complex administrative set up may be overcame by quick wins and longer-term reforms applying different forms of intergovernmental arrangements and community based mechanisms. Voluntarily mergers of municipalities to increase efficiency failed in majority of cases, even in highly developed countries. Therefore, BiH shall rather apply mechanisms of vertical and horizontal cooperation implemented in Switzerland, Sweden and Belgium. Ethnic groups may benefit from specific cultural and education solutions and Belgium model seems to be applicable in $\mathrm{BiH}$, making different tiers equal from legal point of view with jurisdiction over different areas.

Another area for improvement is introduction of performance based mechanisms and asymmetric solutions. Experience of FYR Macedonia is particularly useful in setting competitive environment and awarding best performing local communities. In small countries, subsidiarity principle may apply on upper government levels if that provides optimal balance between efficiency and quality of services. It is not always the best solution to have public services provided at first tier of subnational government, in particular if there is no institutional and fiscal capacity and/or economy to scale.

External and internal push factors may be also crucial for success or failure of decentralization efforts. Croatian 
example shows that EU accession indeed may be a strong push factor in accelerating public sector reforms. In 2016 $\mathrm{BiH}$ got $\mathrm{EU}$ candidate status and it is realistic to expect that it will be strong push factor for $\mathrm{BiH}$ as well. Slovakian case shows that even if there is no ethnic challenges, neither intra-state conflict, it may be hard to find political consensus, regardless EU membership aspirations.

Fiscal independence varies significantly among analyzed countries and still majority of European developed countries have relatively low share of local taxes in total taxes collected. In transition countries, municipality budgets are highly dependent on upper government level transfers. In $\mathrm{BiH}$, these transfers represent on average $65 \%$ of municipal budgets, while EU average is $47 \%$. The measures on further fiscal decentralization seems to be premature for $\mathrm{BiH}$ environment as there is many model deficiencies to be resolved to ensure functionality and efficiency. De-concentration models are also good alternative as proved in case of Slovakia. Still, allocation mechanisms may be powerful tool of upper levels of government in promoting and encouraging efficiency among municipalities. For example, awarding municipalities that use cooperation mechanisms or granting more power to municipalities that are fiscally responsible (or vice versa, fining those that are not).

For sure, there is no one, best approach to decentralization process. Every country has to find the best model customized to address specifics of the historical, cultural, political and economic development. However, rich experience of developed and transitional countries as well as functional decentralization systems is very useful input to find right formula for $\mathrm{BiH}$.

\section{REFERENCES}

[1] Lockwood, B. 2006. The political economy of decentralization in Handbook of Fiscal Federalism Eds Ahmad E, Brosio G. Edward Elgar, Cheltenham.

[2] Harstad, B. 2008. Do Side Payments Help? Collective Decisions and Strategic Delegation. Journal of the European Economic Association 6(2-3) 468-477.

[3] Keating, M. 1999. Asymmetrical government: multinational states in an integrating Europe. Publius 29 (1).

[4] Kroeger, A. 2002. Analysis: Bosnia at the crossroads. BBC News, 4 October 2002, available at http://news.bbc.co.uk/1/hi/world/europe/2299801.stm, accessed 22 November 2017.

[5] Engelbrekt, K. E. 2004. Back to basics? International engagement and recurring conflict in Southeastern Europe. Global Review of Ethnopolitics 3(3/4), 44-59.

[6] Arvanitopoulos C. \& Tzifakis, N. 2008. Implementing reforms in Bosnia and Herzegovina: The challenge of the constitutional process. European View 7(1).
[7] Bose, S. 2002. Bosnia after Dayton: Nationalist Partition and International intervention. London: Hurst.

[8] Belloni, R. 2004. Peacebuilding and consociational electoral engineering in Bosnia and Herzegovina. International Peacekeeping 11(2), 334-53.

[9] McGarry J., O'Leary B. and Simeon R. 2008. Integration or accommodation? The enduring debate in conflict regulation. In Choudhry, S. (ed.) Constitutional Design for Divided Societies: Integration or Accommodation? Oxford: Oxford University Press.

[10] Lijphart, A. 1977. Democracy in plural societies: A comparative exploration. New Haven: Yale University Press.

[11] Dillinger W. 1994. Decentralization and its impact for urban service delivery. Urban Management Program Discussion Paper 16. World Bank, Washington.

[12] World Bank. 2000. Overview of Decentralization. Washington: World Bank.

[13] Rodriguez-Pose, A. \& Gill, N. 2003. The global trend towards devolution and its implications. Environment and Planning, Government and Policy, 21, 333-351.

[14] Aristovnik A. 2012. Fiscal decentralization in Eastern Europe: Trends and selection issues. Transylvanian Review of Administrative Sciences, No. 37 E/2012, pp. 5-22.

[15] Inman R.P. \& Rubinfeld D.L. 2000. Federalism. In Bouckaert, B, de Geest G.: The Encyclopedia of Law and Economics. Edward Elgar.

[16] Storper M. 2005. Society, community and economic development. Studies in Comparative Development 39.

[17] OECD.2012. Territorial Reviews: Sweden 2010.

[18] Billiet, J., Maddens, B., \& Frognier, A. 2006. Does Belgium (still) exist? Differences in political culture between Flemings and Walloons. West European Politics, 29 (5), 912-932.

[19] Benz, M \& Stutzer, A. 2002. Are Voters Better Informed When They Have a Larger Say in Politics?. Working Paper No. 119. Institute for Empirical Economic Research, University of Zurich.

[20] Lyon, A. 2011. Municipal Decentralization in the Republic of Macedonia: Preserving a Multi-Ethnic State?" Federal Governance, vol. 8 no. 3, pp. 28-49.

[21] Bieberr, F. 2005. Partial Implementation, Partial Success: The Case of Macedonia. In Russell, D. \& O'Flynn, I. , New Challenges for Power-Sharing: Institutional and Social Reform in Divided Societies, London: Pluto

[22] Latifi, V. 2001. Macedonian Unfinished Crisis: Challenges in the Process of Democratization and Stabilization. Skopje: Konrad Adenauer Stiftung.

[23] UNDP. 2008. Decentralization in the Europe and CIS Region. Discussion Paper, Democratic Governance Practice, Bratislava Regional Centre

[24] Zakošek, N. 2002. Das politische System Kroatiens. In Ismayr, W. (ed.), Die politischen Systeme Osteuropas, pp. 639-680, Opladen, Leske + Budrich. 
[25] Cabada, L. 2008. Decentralization Processes in Croatia and Slovenia. In: Politics in Central Europe 4, 1, pp. 24-37. URN: http://nbn-resolving.de/urn:nbn:de:0168-ssoar-62252.

[26] Jacko, T. \& Malikova, L. 2013. A chance to restart Public Administration Reform in Slovakia. CEE Annual
Conference "Regionalisation and Inter-regional Cooperation" Belgrade, Serbia.

[27] Benhabib, S. 2002. The Claims of Culture: Equality and Diversity in the Global Era, Princeton. New Jersey: Princeton University Press. 